\title{
SOBREVIVENCIA DE Salmonella typhimurium EN MELÓN 'CANTALOUPE' DURANTE EL ALMACENAMIENTO REFRIGERADO EN ATMÓSFERAS CONTROLADAS
}

\section{SURVIVAL OF Salmonella typhimurium ON 'CANTALOUPE' MELON DURING COLD STORAGE UNDER CONTROLLED ATMOSPHERES}

\author{
Patricia Landa Salgado ${ }^{1}$, Ana M. Hernández Anguiano ${ }^{*}$, Joel Corrales García ${ }^{2}$, Gustavo Mora Aguilera $^{1}$ y \\ Cristóbal Chaidez Quiroz ${ }^{3}$
}

${ }^{1}$ Colegio de Postgraduados. Km 36.5, carr. México-Texcoco, Montecillo, Texcoco Edo de México. (595) 95-20200 ext. 1083 , 1602 (fax). ${ }^{2}$ Universidad Autónoma Chapingo. ${ }^{3}$ Centro de Investigación en Alimentación y Desarrollo, A. C.

\section{RESUMEN}

Se analizó la sobrevivencia de Salmonella typhimurium sola y asociada con Rhizopus sp. en frutos de melón 'Cantaloupe' (Cucumis melo L.) var. reticulatus durante el almacenamiento en frío con atmósferas controladas (AC). Frutos de tamaño uniforme se inocularon con $8.2 \log _{10}$ UFC de una cepa de $S$. typhimurium ATCC2356, resistente a kanamicina $(\mathrm{Km})$, y se almacenaron en las atmósferas: $\mathrm{AC}_{1} \operatorname{con} \mathrm{O}_{2} 3 \%, \mathrm{CO}_{2} 12 \%$ y $\mathrm{N}_{2} 85 \% ; \mathrm{AC}_{2} \operatorname{con~} \mathrm{O}_{2} 5 \%, \mathrm{CO}_{2} 15 \%$ y $\mathrm{N}_{2} 80 \%$; y aire con $\mathrm{O}_{2} 20.95 \%, \mathrm{CO}_{2} 0.03 \%$ y $\mathrm{N}_{2} 78.08 \%$, a $3.7^{\circ} \mathrm{C}$ y humedad relativa (HR) de 93.6 $\pm 5.9 \%$ por $192 \mathrm{~h}$. Cada 48 h se extrajo un fruto en el que se tomaron muestras de tejido inoculado para pruebas de detección en agar entérico Hektoen con $\mathrm{Km}\left(50 \mu \mathrm{g} \mathrm{mL}^{-1}\right)$. Los resultados mostraron que $S$. typhimurium puede sobrevivir en la superficie del fruto en las atmosferas refrigeradas $\mathrm{AC}_{1}, \mathrm{AC}_{2}$ y aire; sin embargo, bajo estas condiciones la población bacteriana registró un decremento $\left(P \leq 0.05\right.$ ) de 3.7, 4.3 y $4.75 \log _{10}$ UFC por fruto, respectivamente. La presencia de Rhizopus sp. no afectó la capacidad de sobrevivir de la bacteria ni el nivel de su población en $\mathrm{AC}_{2}$ y aire en condiciones similares de temperatura y HR. Se evidencia así la capacidad de $S$. typhimurium para sobrevivir en atmósferas con alta concentración de $\mathrm{CO}_{2}$ y condiciones adversas de temperatura, así como de la importancia de prevenir la contaminación del melón 'Cantaloupe' durante su producción y comercialización.

Palabras clave: Cucumis melo, Salmonella typhimurium, Rhizopus, atmósferas controladas.

\section{SUMMARY}

The survival of Salmonella typhimurium alone or associated with Rhizopus sp. was analyzed on 'Cantaloupe' melons (Cucumis melo L.) var. reticulatus during cold storage under controlled atmospheres (CA). Melons of uniform size were inoculated with $8.2 \log _{10}$ CFU of a strain of S. typhimurium ATCC2356, kanamycin resistant $(\mathrm{Km})$ and stored under the atmospheres: $\mathrm{AC}_{1}$ at $\mathrm{O}_{2} 3 \%, \mathrm{CO}_{2} 12 \%$ and $\mathrm{N}_{2} 85$ $\%$; $\mathrm{AC}_{2}$ at $\mathrm{O}_{2} 5 \%, \mathrm{CO}_{2} 15 \%$ and $\mathrm{N}_{2} 80 \%$; and air $\left(\mathrm{O}_{2} 20.95 \%, \mathrm{CO}_{2}\right.$ $0.03 \%$, and $\mathrm{N}_{2} 78.08 \%$ ) at $3.7^{\circ} \mathrm{C}$ and relative humidity (RH) of 93.6 $\pm 5.9 \%$ by $192 \mathrm{~h}$. Every $48 \mathrm{~h}$ inoculated tissue samples were taken from fruits for testing on enteric Hektoen agar with $\mathrm{Km}\left(50 \mathrm{~m} \mathrm{~mL} \mathrm{~L}^{-1}\right)$.
Results showed that $S$. typhimurium can survive on the surface of the fruit in chilled atmospheres $\mathrm{AC}_{1}, \mathrm{AC}_{2}$ and air, although under these conditions the bacteria showed a decrease $(P \leq 0.05)$ in the population of 3.7, 4.3 and $4.7 \log _{10} \mathrm{CFU}$ per fruit, respectively. The presence of Rhizopus sp. did not affect the bacteria ability to survive or its population level at similar conditions of temperature and RH. Therefore, it is demonstrated the ability of S. typhimurium to survive in atmospheres with high $\mathrm{CO}_{2}$ concentration and adverse temperature conditions, and the importance to prevent the contamination of 'Cantaloupe' melons during its production and marketing.

Index words: Cucumis melo, Salmonella typhimurium, Rhizopus, controlled atmospheres.

\section{INTRODUCCIÓN}

Salmonella es una bacteria enteropatógena que en las últimas dos décadas se ha relacionado con numerosos brotes asociados con el consumo de melón 'Cantaloupe' ( $\mathrm{Cu}$ cumis melo L.) (Calvin, 2003). Debido a la importancia sanitaria y económica de Salmonella varios investigadores se han dedicado a evaluar tratamientos químicos (Brackett, 1992; Ukuku y Sapers, 2006), físicos (Zhuang et al., 1995; Amanatidou et al., 1999; Wuytack et al., 2003; Ukuku, 2005; Daş et al,. 2006) y biológicos (Richards y Beuchat, 2004) para lograr un control efectivo contra este patógeno. Sin embargo, actualmente se carece de un tratamiento $100 \%$ efectivo contra Salmonella (Ukuku y Sapers, 2006).

Hay reportes de que algunos hongos como Botrytis, Cladosporium, Geotrichum, Penicillium y Rhizopus, integrantes de la microflora natural de la superficie de los productos hortofrutícolas frescos, pueden inducir cambios en textura y $\mathrm{pH}$ del tejido los cuales favorecen la sobreviven- 
cia y proliferación de otros microorganismos (Draughon $e t$ al., 1988; Conway et al., 2000; Riordan et al., 2000; Wade y Beuchat, 2003b). Específicamente, se ha reportado (Wells y Butterfield, 1999) que en presencia de Rhizopus el nivel de población de $S$. typhimurium se incrementa de 10 a 100 veces en papa (Solanum tuberosum L.), cebolla (Allium cepa L.) y tomate (Lycopersicum esculentum L.), precortados y almacenados a $25{ }^{\circ} \mathrm{C}$ bajo atmósfera normal de aire.

Parte de la cadena productiva del melón 'Cantaloupe' involucra el almacenamiento antes de su distribución y comercialización. Las atmósferas controladas (AC) y atmósferas modificadas (AM) se utilizan para incrementar la vida postcosecha de varios productos agrícolas (Kader, 2002), y de manera reciente se usan para inhibir el crecimiento de hongos como Botrytis cinerea, Rhizopus stolonifer y Penicillium discolor durante postcosecha (Hoogerwerf et al., 2002) y para controlar algunos patógenos de humanos como Listeria monocytogenes (Conway et al., 2000), Salmonella enteritis (Nychas y Tassou, 1996) y $S$. typhimurium (Amanatidou et al., 1999).

Por la importancia que para los productores, transportistas y comerciantes tiene el contar con información sobre el impacto de las atmosferas controladas en la calidad sanitaria de los productos hortofrutícolas frescos, en este trabajo el objetivo principal fue analizar la sobrevivencia de $S$. typhimurium sola y asociada con Rhizopus en melón 'Cantaloupe', durante el almacenamiento refrigerado en las atmósferas controladas recomendadas a nivel comercial para este fruto. Adicionalmente, bajo estas mismas condiciones se registró la capacidad de crecimiento y de internalización de la bacteria en el melón 'Cantaloupe' con la hipótesis de que en condiciones de refrigeración las atmósferas controladas tienen efecto bactericida o bacteriostático en $S$. typhimurium, y de que Rhizopus puede modificar el $\mathrm{pH}$ y la textura de la corteza para favorecer el crecimiento y la internalización de la bacteria en el fruto.

\section{MATERIALES Y MÉTODOS}

\section{Cepas y preparación de inóculo}

Bacteria. Se utilizó la cepa St- $3^{\mathrm{km} 50}$ resistente a kanamicina (Kanamicina A, Sigma Adrich ${ }^{\circledR}$ ), la cual se derivó de una cepa de Salmonella enterica serotipo Typhimurium ATCC23564 (S. typhimurium), donada por el laboratorio de microbiología del Centro de Investigación en Alimentación y Desarrollo A. C. (CIAD) en Culiacán, México. A partir de un cultivo de la cepa $\mathrm{St}-3^{\mathrm{km} 50}$ en glicerol-agua $(50: 50 \mathrm{v} / \mathrm{v})$ mantenida a $-80{ }^{\circ} \mathrm{C}$, se sembró en agar entérico Hektoen (Bioxon®) con kanamicina a concentración de $50 \mu \mathrm{g} \mathrm{mL}^{-1}\left(\mathrm{AEH}-\mathrm{Km}^{50}\right)$. De una colonia de $48 \mathrm{~h}$ de cre- cimiento se tomó masa bacterial y se transfirió a caldo de soya tripticaseína (Difco®, CST) con $\mathrm{Km}^{50}\left(\mathrm{CST}-\mathrm{Km}^{50}\right)$. Después de $18 \mathrm{~h}$ a $37^{\circ} \mathrm{C}$, la suspensión bacterial se centrifugó a $8000 \mathrm{~g}$ por $10 \mathrm{~min}$ y la pastilla (masa bacterial) se resuspendió en $1 \mathrm{~mL}$ de agua buferada peptonada (ABP) a $0.1 \%(\mathrm{p} / \mathrm{v})$. Este procedimiento de lavado/centrifugado se repitió dos veces para recuperar nuevamente la bacteria en ABP a $0.1 \%$. Se estimó la población (UFC $\mathrm{mL}^{-1}$ ) en AEH-Km ${ }^{50}$ a $37{ }^{\circ} \mathrm{C}$ y la suspensión se mantuvo en hielo hasta su utilización.

Hongo. Se utilizó una cepa de Rhizopus sp. aislada de melones 'Cantaloupe' naturalmente infectados y mantenida en papa-dextrosa agar (PDA) y glicerol $50 \%$ a $5{ }^{\circ} \mathrm{C}$. Para la preparación del inóculo, la cepa se reactivó en cajas Petri con PDA a $20{ }^{\circ} \mathrm{C}$, y después de $48 \mathrm{~h}$ de crecimiento se depositaron $10 \mathrm{~mL}$ de agua destilada estéril sobre la superficie del medio para dispersar las esporas del hongo desarrollado, con una varilla de vidrio estéril. La suspensión de esporas se filtró a través de una gasa estéril y se centrifugó a $16000 \mathrm{~g}$ por $5 \mathrm{~min}$. Las esporas se resuspendieron en agua destilada estéril y el proceso de lavado/centrifugado se repitió dos veces. Posteriormente, se determinó el nivel de la población de esporas en una cámara de recuento tipo Newbauer (Zuzi®) y la suspensión se mantuvo en hielo hasta su utilización como inóculo.

\section{Establecimiento de cámaras con atmósferas contro- ladas (AC)}

Los tratamientos con $\mathrm{AC}$ se establecieron en una cámara frigorífica con temperatura promedio de $5 \pm 1.5{ }^{\circ} \mathrm{C}$ y con base en mezclas comerciales estándar certificadas (INFRA, S.A. de C.V.), contenidas en tanques presurizados de $6 \mathrm{~m}^{3}$ de capacidad conectados a un sistema de flujo controlado $\left(24 \mathrm{~mL} \mathrm{~min}^{-1}\right)$ por un tablero, lo que permitió la dosificación al interior de cámaras de AC $(5 \mathrm{~L}$ de capacidad) a través de mangueras de plástico y látex. Para introducir la mezcla gaseosa a las cámaras de $\mathrm{AC}$ y al mismo tiempo evitar su acumulación mediante su salida continua, en la tapadera de estas cámaras se hicieron dos perforaciones circulares ( $1.7 \mathrm{~cm}$ de diámetro), en las cuales se instaló un puerto hermético de entrada y uno de salida. La hermeticidad de estas cámaras se logró mediante cinta de Teflón® colocada en la cuerda de cierre de sus tapaderas. Los tratamientos evaluados se denominaron: atmósfera controlada $1\left(\mathrm{AC}_{1}\right)$ con $\mathrm{O}_{2} 3 \%, \mathrm{CO}_{2} 12 \%$ y $\mathrm{N}_{2} 85 \%$; atmósfera controlada $2\left(\mathrm{AC}_{2}\right)$ con $\mathrm{O}_{2} 5 \%, \mathrm{CO}_{2} 15 \%$ y N 2 $80 \%$; y aire (Testigo) cuya composición aproximada de acuerdo con Kader (2002) es $\mathrm{O}_{2} 20.95 \%, \mathrm{CO}_{2} 0.03 \%$ y $\mathrm{N}_{2} 78.08 \%$. Dentro de cada cámara se colocó un fruto (unidad experimental), y de cada tratamiento (mezcla gaseosa y periodo de exposición) se hicieron tres repeticiones (tres unidades experimentales). 


\section{Preparación e inoculación de frutos de melón 'Canta- loupe'}

Se utilizaron melones 'Cantaloupe' con un promedio de $10.4{ }^{\circ}$ Brix de sólidos solubles totales; es decir, melones de buena y muy buena calidad comercial, de acuerdo con Infoaserca (2000), adquiridos de la Central de Abastos de la Ciudad de México durante los años 2006 y 2007. El tamaño de los frutos fue uniforme, y correspondió a una clasificación de 15 por caja. Previo a la inoculación, los frutos se lavaron con agua corriente y jabón, se desinfectaron superficialmente por aspersión con $0.02 \%$ de hipoclorito de sodio $(\mathrm{NaClO})$ por $3 \mathrm{~min}$, y se enjuagaron con agua destilada estéril. Después de secarse a $24^{\circ} \mathrm{C}$, los frutos se colocaron en las cámaras de $\mathrm{AC}$, previamente desinfectadas con alcohol $70 \%$ y en los costados de cada uno se marcaron con un marcador indeleble dos regiones de inoculación.

Para la inoculación de frutos se usaron dos protocolos: 1) S. typhimurium, y 2) S. typhimurium + Rhizopus sp. En el primero se depositaron $100 \mu \mathrm{L}$ de suspensión bacterial (con $10^{8.1}$ UFC en promedio) en la superficie de una de las regiones de inoculación y $100 \mu \mathrm{L}$ de agua (testigo) en la otra. En el segundo, primero se depositaron $40 \mu \mathrm{L}$ de una suspensión de esporas (con $6.1 \times 10^{4}$ esporas) de Rhizopus sp. y $24 \mathrm{~h}$ después $100 \mu \mathrm{L}$ de suspensión bacterial de $S$. typhimurium; ambos, bacteria y hongo, en las regiones de inoculación. Cada esquema de inoculación constó de 12 frutos, e inmediatamente después de la inoculación las cámaras de $\mathrm{AC}$ se cerraron y se conectaron al sistema de flujo controlado de intercambio gaseoso $\mathrm{AC}_{1}, \mathrm{AC}_{2}$ y aire.

\section{Muestreo y análisis microbiológico}

De cada atmósfera estudiada se extrajeron tres frutos cada $48 \mathrm{~h}$ durante el periodo de almacenamiento, para determinar sobreviviencia, crecimiento e internalización de $S$. typhimurium. De la región inoculada de cada fruto se tomó una muestra de tejido con un sacabocados de acero inoxidable de $5.8 \mathrm{~cm}$ de diámetro y se depositó en papel aluminio para separar, con un bisturí, la corteza y el tejido de $5 \mathrm{~mm}$ y $10 \mathrm{~mm}$ de profundidad. El tejido seccionado se colocó por separado en bolsas Ziploc $\circledast(16.5 \mathrm{~cm}$ x 14.9 $\mathrm{cm})$, se pesó en una balanza analítica y se mantuvo en hielo para su procesamiento y análisis. Tanto el papel aluminio como las bolsas Ziploc® se esterilizaron previamente con luz ultravioleta por $15 \mathrm{~min}$. Las muestras de tejido se procesaron en una cámara de bioseguridad tipo II (ENVIRCO® Corporation 805-5-65-98 PN 3137) como indican Amador et al. (2000). A cada muestra se le adicionó un volumen de ABP $0.1 \%$ equivalente a su peso, se frotó manualmente y de la suspensión obtenida se tomaron 100 $\mu \mathrm{L}$ para ser sembrados en cajas Petri con $\mathrm{AEH}-\mathrm{Km}^{50}$.
Después de que las cajas se incubaron a $37^{\circ} \mathrm{C}$ por $48 \mathrm{~h}$, se contaron las colonias de Salmonella desarrolladas en el medio y se aislaron algunas de ellas en AEH- $\mathrm{Km}^{50}$ para su posterior confirmación por PCR (Rahn et al., 1992).

Para el aislamiento de Rhizopus se tomaron $100 \mu \mathrm{L}$ de cada una de las suspensiones obtenidas en ABP $0.1 \%$ y se sembraron en cajas Petri con PDA acidificado con ácido cítrico $10 \%\left(14 \mathrm{~mL} \mathrm{~L}^{-1}\right)$ y se incubaron a $20^{\circ} \mathrm{C}$ por $24 \mathrm{~h}$. Después de la incubación se registró el crecimiento del hongo y se hicieron observaciones al microscopio compuesto para su identificación, de acuerdo con las características morfológicas (Barnett y Hunter, 1998).

\section{Determinación de textura y pH del fruto}

La textura y el $\mathrm{pH}$ de la región inoculada de frutos de melón con Salmonella y Salmonella + Rhizopus sp., se determinaron al cabo de cada periodo de almacenamiento. La textura se determinó por penetrometría con un texturómetro (Stable Micro System, TA-XT2i, Texture Analyser®, England) y una sonda tipo aguja (Needle probe, Bate No. 3426) de acuerdo con las recomendaciones del instructivo del equipo para melón. Los parámetros de penetración establecidos fueron: velocidad de pre-ensayo $1.5 \mathrm{~mm} \mathrm{~s}^{-1}$; velocidad de ensayo $5 \mathrm{~mm} \mathrm{~s}^{-1}$; distancia de penetración 20 $\mathrm{mm}$. Cada fruto se colocó e inmovilizó con pequeñas calzas sobre una superficie plana, justo debajo de la sonda, para que ésta penetrara en forma perpendicular. La zona de penetración se ubicó a una distancia entre 0.5 y $1 \mathrm{~cm}$ del punto de inoculación en la región ecuatorial. Los datos se procesaron con un programa automatizado integrado (Windows ${ }^{\circledR}$ software, Texture Expert, Stable Micro Systems Ltd, versión 1.20, en español). Los resultados se expresaron en gramos fuerza $\left(\mathrm{g}_{\mathrm{f}}\right)$ necesarios para la penetración en el tejido. El pH se midió en un potenciómetro con electrodo tipo aguja $\left(\mathrm{pH} /{ }^{\circ} \mathrm{C}\right.$ meter with GLP; Hanna ${ }^{\circledR}$ Instruments HI 98230, Rumania).

\section{Análisis estadístico}

Los datos de población bacteriana se analizaron con el programa estadístico Statistical Analysis Software (SAS Institute, 1998) en un arreglo de parcelas divididas, con prueba de comparación de medias de Tukey $(\mathrm{P} \leq 0.05)$. Los datos de textura y $\mathrm{pH}$ del melón se analizaron como mediciones repetidas en el tiempo con el módulo GLM de SAS (Littell et al., 1998). Se probó el efecto de la interacción Tiempo x Tratamiento para determinar si en alguna fecha particular la medición de al menos uno de los tratamientos mostraba una respuesta diferente. Adicionalmente, se utilizó la prueba de t para comparar la textura y $\mathrm{pH}$ de los frutos dentro de cada tipo de atmósfera y periodo de exposición. 


\section{RESULTADOS Y DISCUSIÓN}

\section{Sobrevivencia de Salmonella typhimurium en frutos al- macenados en AC}

La cepa St- $3^{\mathrm{km} 50}$ de $S$. typhimurium sobrevivió en la superficie (cáscara) del fruto de melón 'Cantaloupe' en las atmósferas $\mathrm{AC}_{1}, \mathrm{AC}_{2}$ y aire durante $192 \mathrm{~h}$ a $3.7^{\circ} \mathrm{C}$ y $\mathrm{HR}$ de $93.6 \pm 5.9 \%$. Sin embargo, la población de la bacteria decreció $(\mathrm{P} \leq$ 0.05) durante el almacenamiento: 3.7, 4.3 y $4.7 \log _{10} \mathrm{UFC}$ en $\mathrm{AC}_{1}, \mathrm{AC}_{2}$ y aire, respectivamente, y la principal reducción se registró en las primeras $48 \mathrm{~h}$ de almacenamiento (Figura 1). Los resultados del análisis de los tejidos a $5 \mathrm{~mm}$ y $10 \mathrm{~mm}$ de profundidad mostraron que durante el almacenamiento no ocurrió internalización de $S$. typhimurium en el fruto porque no se recuperó a la bacteria en $\mathrm{AEH}-\mathrm{Km}^{50}$. Las atmósferas $\mathrm{AC}_{1}$ y $\mathrm{AC}_{2}$, recomendadas a nivel comercial para alargar la vida postcosecha del melón 'Cantaloupe' (Kader, 2002) no tuvieron efecto bactericida o bacteriostático para S. typhimurium. Los resultados también mostraron que $S$. typhimurium tiene habilidad para sobrevivir bajo condiciones adversas de temperatura y de baja disponibilidad de nutrientes en la superficie del fruto. Estudios preliminares reportaron que los serotipos de Salmonella no crecen por debajo de $7{ }^{\circ} \mathrm{C}$ (Blackburn y McClure, 2002) pero pueden sobrevivir en jugo de naranja (Citrus $\times$ sinensis ) a $4{ }^{\circ} \mathrm{C}$ (Eblen et al., 2004). La capacidad de la bacteria de sobrevivir bajo condiciones adversas de temperatura y sin disponibilidad de nutrientes puede estar relacionada con su habilidad para formar rápidamente biopelículas (células bacteriales embebidas en material polimérico extracelular) que la protegen de factores externos del ambiente (Annous et al., 2005).

El riesgo que representa la capacidad de sobrevivir de $S$. typhimurium en atmósferas ricas en $\mathrm{CO}_{2}$ y temperaturas de refrigeración, las cuales serían perjudiciales para otros patógenos (Enfors y Molin, 1980), es el de que contamine la parte comestible del fruto de melón durante el cortado para su consumo. La parte comestible del fruto presenta condiciones óptimas de crecimiento para la bacteria como la disponibilidad de nutrientes en ambiente acuoso (Gagliardi et al., 2003; Ukuku y Sapers, 2006). En general se considera que el mantener los productos en refrigeración puede controlar el crecimiento de patógenos como Salmonella; sin embargo, la refrigeración de melón precortado no es una práctica común. Por lo anterior, el consumo de melón 'Cantaloupe' contaminado con Salmonella es un riesgo grande para la salud del consumidor, como lo evidencian los numerosos brotes de salmonelosis asociados con este producto, ocurridos en la última década (Calvin, 2003).

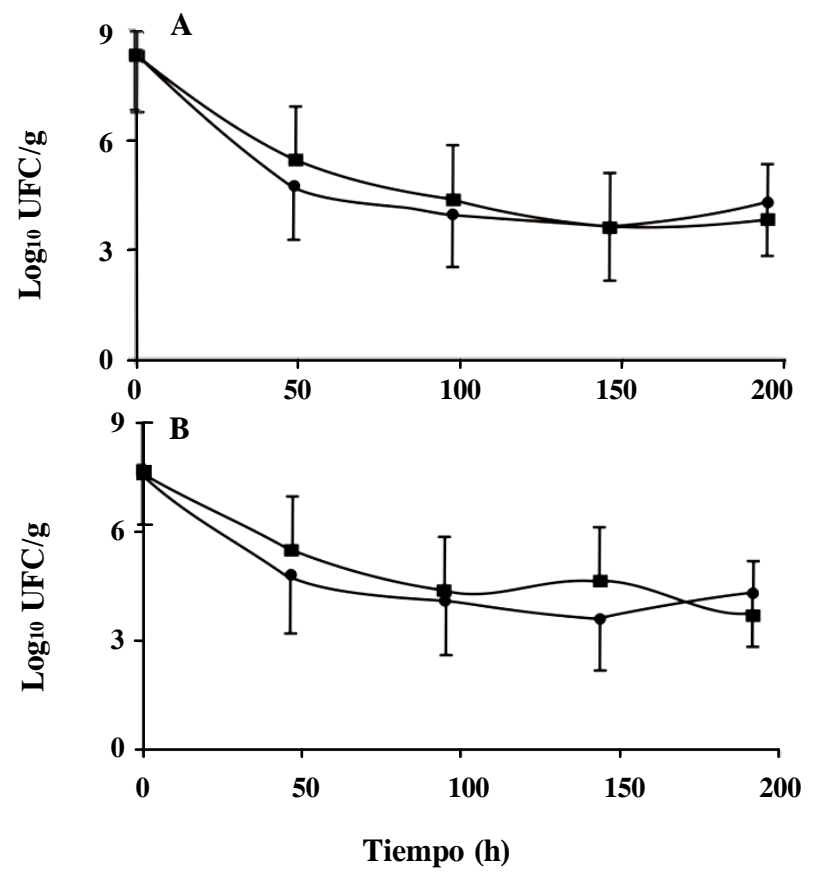

Figura 1. Sobrevivencia de Salmonella typhimurium en la superficie del fruto de melón 'Cantaloupe' en las atmósferas: (A) $\mathrm{AC}_{1}$ con $\mathrm{O}_{2} 3 \%$, $\mathrm{CO}_{2} 12 \%$ y N2 $85 \%$ (Símbolo a) y aire (Símbolo •); y (B) $\mathrm{AC}_{2}$ con $\mathrm{O}_{2} 5$ $\%, \mathrm{CO}_{2} 15 \%$ y $\mathrm{N}_{2} 80 \%$ (Símbolo a) o aire (Símbolo •), a $3.7^{\circ} \mathrm{C}$ y HR de 93.6 \%. Cada valor representa el promedio de dos experimentos independientes; cada experimento constó a su vez de tres repeticiones (n $=3$ ). Inóculo inicial: en A de 7.7 y en B de $8.8 \log _{10}$ UFC/100 $\mu \mathrm{L}$. Las barras verticales representan el error estándar.

\section{Sobrevivencia de Salmonella typhimurium en presencia de Rhizopus}

La presencia de Rhizopus sp. no afectó el patrón de sobrevivencia de la cepa St- $3^{\mathrm{km} 50}$ de Salmonella typhimurium en la superficie del fruto de melón 'Cantaloupe' en $\mathrm{AC}_{2} \mathrm{y}$ aire a $3.2{ }^{\circ} \mathrm{C}$ y $\mathrm{HR}$ de $99.6 \%$. A las $144 \mathrm{~h}$ después de la inoculación, la población de $S$. typhimurium fue ( $\mathrm{P} \leq$ 0.05 ) menor que la población inicial (Figura 2). La principal reducción en la población ocurrió durante las primeras $48 \mathrm{~h}$. Al final del almacenamiento, la reducción total registrada fue de 4.4 y $4.5 \log _{10} \mathrm{UFC} \mathrm{g}^{-1}$ en $\mathrm{AC}_{2} \mathrm{y}$ aire, respectivamente. La presencia del hongo no favoreció la internalización de la bacteria ya que no se detectaron células de Salmonella en AEH- $\mathrm{Km}^{50}$ cuando se sembraron muestras de suspensiones, en ABP $0.1 \%$, de los tejidos de $5 \mathrm{~mm}$ y $10 \mathrm{~mm}$ de profundidad. 


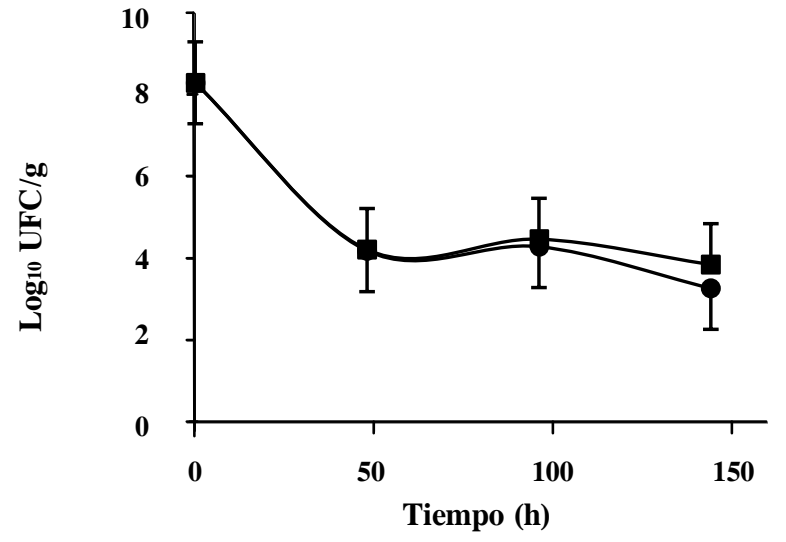

Figura 2. Sobrevivencia de Salmonella typhimurium en la superficie de frutos de melón 'Cantaloupe', en presencia de Rhizopus sp., en atmósferas $\mathrm{AC}_{2} \operatorname{con} \mathrm{O}_{2} 5 \%, \mathrm{CO}_{2} 15 \%$ y N2 $80 \%$ (Símbolo a) y aire (Símbolo •) a $3.2{ }^{\circ} \mathrm{C}$ y $\mathrm{HR}$ de $99.6 \%$. Cada valor representa el valor promedio de dos experimentos independientes; cada experimento constó de tres repeticiones $(n=3)$. Inóculo: Salmonella 8.6 $\log _{10} \mathrm{UFC} / 100 \mu \mathrm{L}$; Rhizopus, $6.15 \times 10^{4}$ esporas $/ 40 \mu \mathrm{L}$. Las barras representan el valor estándar.

En las regiones inoculadas con el hongo se observó ligero crecimiento micelial oscuro en la superficie del fruto. En observaciones al microscopio compuesto se encontraron escasas esporas germinadas; el resto $(99.52 \%)$, estaba sin germinar. Estas últimas germinaron posteriormente cuando se depositaron en PDA acidificado e incubaron a $20^{\circ} \mathrm{C}$, lo que evidenció que el hongo mantuvo su viabilidad en la superficie del fruto. Estos resultados indican que la temperatura, más que la concentración de $\mathrm{O}_{2} \mathrm{y} \mathrm{CO}_{2}$ de la atmósfera, fue un factor importante en la germinación de las esporas. Mass (1998) reportó que Rhizopus no crece por debajo de $5{ }^{\circ} \mathrm{C}$, por lo que no es de esperarse que el hongo infecte por penetración directa de la cáscara de melón por producir una lesión a través de la cual Salmonella pudiera penetrar.

\section{Textura y pH}

El análisis de repeticiones en el tiempo indicó que la textura promedio de los frutos de melón 'Cantaloupe' inoculados con Salmonella y con Salmonella + Rhizopus fue similar sin diferencias $(\mathrm{P} \leq 0.05)$ entre mezcla gaseosa y periodo de exposición (Cuadro1). Según García-Sahagún et al. (2005), la madurez a la que los melones se cosechan y la temperatura a la que se almacenan afecta la textura; los frutos cosechados maduros presentaron textura de $2510 \mathrm{~g}_{\mathrm{f}}$ la cual decreció a 810 y 1300 gf cuando se almacenaron a 2 y $5{ }^{\circ} \mathrm{C}$, respectivamente. En este trabajo los frutos de melón registraron valores promedio iniciales de textura de $650 \mathrm{~g}_{\mathrm{f}}$, de lo que se infiere que la temperatura de $3.2{ }^{\circ} \mathrm{C}$ a la cual se mantuvieron durante el almacenamiento no afectó $(P \leq 0.05)$ su textura. El análisis de muestras repetidas en el tiempo y la prueba de $t$ son consistentes y no muestran diferencias entre tratamientos.

El pH del fruto de melón fue estadísticamente igual (P $\leq 0.05$ ) entre tratamientos, independientemente de la presencia o ausencia de Rhizopus $s p$. La prueba de $t$ indicó que este resultado aplica para ambas atmósferas (Cuadro 1). En la mayoría de los estudios de las asociaciones de patógenos de humanos con hongos fitopatógenos se han reportado cambios en $\mathrm{pH}$ del tejido inoculado de hasta 2 \pm 1 unidades (Conway et al., 2000; Richards y Beuchat, 2004; Wade y Beuchat, 2003 a, b). En este trabajo no se registraron cambios significativos en $\mathrm{pH}$ en tejido inoculado con Rhizopus sp en $\mathrm{AC}_{2}$ y aire. Esto puede estar relacionado con la baja germinación de las esporas en la superficie y por consiguiente con la ausencia de infección del tejido interno, ya que no se recuperó el hongo de tejidos a $5 \mathrm{~mm}$ y $10 \mathrm{~mm}$ de profundidad. No obstante, cabe destacar que el $\mathrm{pH}$ de frutos con Rhizopus sp fue menor ( $\mathrm{P} \leq$ 0.07) que el registrado en frutos sin el hongo, cuando se mantuvieron bajo la atmosfera $\mathrm{AC}_{2}$ a $3.2^{\circ} \mathrm{C}$ por $144 \mathrm{~h}$.

Cuadro 1. Efecto de Rhizopus sp. en el pH y la textura de frutos de melón 'Cantaloupe' inoculados con S. typhimurium y almacenados en las atmósfera controlada (AC) ${ }^{\dagger}$ y aire ${ }^{\dagger \dagger}$ a $3.2{ }^{\circ} \mathrm{C}$ y HR de $99.6 \%(\mathrm{n}=3)$.

\begin{tabular}{|c|c|c|c|c|c|c|c|}
\hline \multirow[t]{2}{*}{ Atmósfera } & \multirow[t]{2}{*}{ Tiempo (h) } & \multicolumn{2}{|c|}{$\mathrm{pH}$} & \multirow{2}{*}{$\begin{array}{c}\text { Prueba de } \mathrm{t} \\
\text { para } \mathrm{pH}\end{array}$} & \multicolumn{2}{|c|}{ Textura $\left(g_{f}\right)$} & \multirow{2}{*}{$\begin{array}{l}\text { Prueba de t para } \\
\text { textura }\end{array}$} \\
\hline & & $\mathrm{SRh}^{\top}$ & $\mathrm{CRh}^{19}$ & & SRh & CRh & \\
\hline \multirow[t]{2}{*}{$\mathrm{AC}_{2}$} & 48 & - & $6.4 \pm 0.07$ & - & $495.5 \pm 275.3$ & $629.9 \pm 35.3$ & ns \\
\hline & 144 & $6.5 \pm 0.06$ & $6.3 \pm 0.03$ & ns & $701.1 \pm 98.1$ & $700.2 \pm 26.9$ & ns \\
\hline \multirow[t]{2}{*}{ Aire } & 48 & - & $6.2 \pm 0.03$ & ns & $826.1 \pm 19.7$ & $619.5 \pm 100.1$ & ns \\
\hline & 144 & $6.4 \pm 0.03$ & $6.4 \pm 0.09$ & ns & $654.8 \pm 35.9$ & $657.9 \pm 165.8$ & ns \\
\hline
\end{tabular}

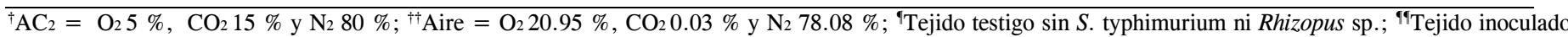
con $8.6 \log _{10} \mathrm{UFC} / 100 \mu \mathrm{L}$ de $S$. typhimurium y $6.15 \times 10^{4}$ esporas $/ 40 \mu \mathrm{L}$ de Rhizopus sp.

- Dato no estimado. Los valores entre paréntesis indican el error estándar $(n=3)$. 


\section{CONCLUSIONES}

Salmonella typhimurium tiene capacidad de sobrevivir en la superficie de frutos de melón 'Cantaloupe' almacenados en atmósferas controladas como $\mathrm{AC}_{1}$ con $\mathrm{O}_{2} 3 \%, \mathrm{CO}_{2}$ $12 \%$ y N $285 \% \mathrm{AC}_{2}$ con $\mathrm{O}_{2} 5 \%, \mathrm{CO}_{2} 15 \%$ y N $280 \%$; y aire con $\mathrm{O}_{2} 20.95 \%, \mathrm{CO}_{2} 0.03 \%$, y $\mathrm{N}_{2} 78.08 \%$ a $3.7{ }^{\circ} \mathrm{C}$, a una humedad relativa de $93.6 \pm 5.9 \%$ por $192 \mathrm{~h}$. Sin embargo, bajo estas condiciones la población bacteriana registró un decremento $(\mathrm{P} \leq 0.05)$ de $3.7,4.3$ y $4.75 \log _{10}$ UFC por fruto, respectivamente. La presencia de Rhizopus sp. no afectó la capacidad de sobrevivir de la bacteria ni el nivel de su población bajo $\mathrm{AC}_{2}$ y aire en condiciones similares de temperatura y HR. Estos resultados evidencian sobre la capacidad de $S$. typhimurium para sobrevivir en atmósferas refrigeradas, así como de la importancia de prevenir la contaminación del fruto de melón 'Cantaloupe' durante su producción y comercialización.

\section{AGRADECIMIENTOS}

Al CONACYT por el apoyo económico a través de la beca de maestría, con numero de becario 201471, a INFRA S.A. de C.V. por el apoyo con parte de las mezclas de atmósferas utilizadas, y al Sr. Adrián Paredes García de la UACh por el apoyo técnico en los muestreos y análisis de muestras.

\section{BIBLIOGRAFÍA}

Amador L R, R D Avilés, M G Eusebio H, R R Fernández, L Mota de la G , R E I Quiñonez, M R Rodríguez (2000) Manual de Laboratorio de Microbiología Sanitaria. 2da ed. Instituto Politécnico Nacional. Escuela Nacional de Ciencias Biológicas. Departamento de Microbiología. $150 \mathrm{p}$.

Amanatidou A, E J Smid, L G M Gorris (1999) Effect of elevated oxygen and carbon dioxide on the surface growth of vegetableassociated micro-organisms. J. Appl. Microbiol. 86:426-438.

Annous B A, E B Solomon, P H Cooke, A Burke (2005) Biofilm formation by Salmonella spp., on cantaloupe melons. J. Food Safety 25:276-286.

Barnett H L, B B Hunter (1998) Ilustrated Genera of Imperfect Fungi. 4th ed. American Phytopatological Society Press. St. Paul MN, USA. $218 \mathrm{p}$.

Blackburn C W, P McClure (2002) Foodborne Pathogens, Hazards, Risk Analysis and Control. CRC Press. Cambridge England. 517 p.

Brackett R E (1992) Shelf stability of fresh produce as influenced by sanitation and disinfection. J. Food Protect. 55:808-814.

Calvin L (2003) Produce, food safety, and international trade: Respose to US foodborne illness outbreaks associated with imported produce. In: International Trade of Food Safety, AER-828. Economic Research Service/USDA. J Buzby (ed). U.S. http://www.ers.usda.gov/publications/aer828/aer828g.pdf. (Julio, 2007)

Conway W S, B Leverentz, R A Saftner, W J Janisiewics, C E Sams, E Leblane (2000) Survival and growth of Listeria monocytogenes on fresh-cut apple slices and its interaction with Glomerella cingulata and Penicillium expansum. Plant Dis. $84: 177-181$
Daş E, G C Gürakan, A Bayındırlı (2006) Effect of controlled atmosphere storage, modified atmosphere packaging and gaseous ozone treatment on the survival of Salmonella Enteritis on cherry tomatoes. Food Microbiol. 23:430-438.

Draughon F A, S Chen, J O Mundt (1988) Metabiotic association of Fusarium, Alternaria, and Rhizoctonia with Clostridium botulinum in fresh tomatoes. J. Food Sci. 53:120-123.

Eblen S B, M O Walderhaug, S Edelson-Mammel, S J Chirtel, A De Jesus, R I Merker, A J Miller (2004) Potential for internalization, grow, and survival of Salmonella and Escherichia coli 0157:H7 in oranges. J. Food Protect. 67:1578-1584

Enfors S O, G Molin (1980) Effect to high concentrations of carbon dioxide on growth rate of Pseudomonas fragi, Bacillus cerus and Streptococcus cremoris. J. Appl. Bacteriol. 48:409-416.

Gagliardi J V, P D Millner, G Lester, D Ingram (2003) On-farm and postharvest processing sources of bacterial contamination to melon rinds. J. Food Protect. 66:82-87.

García-Sahagún M A, I Vargas-Arispuro, A A Gardea-Béjar, M H Tiznado, M A Martínez-Tellez (2005) Chilling injury in cantaloupes melons at two maturity stages. Rev. Fitotec. Mex. 28:161-170.

Hoogerwerf S W, E P W Kets, J Dijksterhuis (2002) High-oxygen and high-carbon dioxide containing atmospheres inhibit growth of associated moulds. Lett. Appl. Microbiol. 35:419-422.

Infoaserca (2000) El melón mexicano; ejemplo de tecnología aplicada. Claridades Agropecuarias: ASERCA 84:1-32. http://www.infoaserca.gob.mx/claridades/revistas.asp (Julio 2007).

Kader A A (2002) Modified atmospheres during transport and storage: In: Postharvest Technology of Horticultural Crops. A A Kader (tec ed). 3rd ed. University of California Agriculture and Natural Resources. USA. pp:135-144.

Littell R C, P R Henry, C J Ammerman (1998) Statistical Analysis of repeated measures data using SAS Procedures. J. Animal Sci. 76:1216-1231.

Mass J L (1998) Compendium of Strawberry Diseases. Ed. APS Press. St. Paul Minnesota. USA. 98 p.

Nychas G J E, C C Tassou (1996) Growth/survival of Salmonella enteritis on fresh poultry and fish under vacuum or modified atmosphere. Lett. Appl. Microbiol. 23:115-119.

Rahn K, A De Grandis, R C Clarke (1992) Amplification of InvA gene sequence of Salmonella typhimurium by polymerase chain reaction as a specific method of detection of Salmonella. Mol. Cellular Probes. London, V. 6. pp:271-279.

Richards G M, L R Beuchat (2004) Metabiotic associations of molds and Salmonella Poona on intact and wounded cantaloupe rind. Int. J. Food Microbiol. 97:327-339.

Riordan D C R, G M Sapers, B A Annous (2000) The survival of Escherichia coli $\mathrm{O} 157: \mathrm{H} 7$ in the presence of Penicillium expansum and Glomerella cingulata in wounds on apples surfaces. J. Food Protect. 63:1637-1642.

SAS Institute (1998) SAS/STAT. Guide for personal computers. Statistical Analysis System, Cary, NC, USA.

Ukuku D O (2005) Effect of sanitizing treatmens on removal of bacteria from cantaloupe surface, and re-contamination with Salmonella. Food Microbiol. 23:289-293.

Ukuku D O, G M Sapers (2006) Microbiological safety issues of fresh melons. In: Microbiology of Fruits and Vegetables. G Sapers , R Gorny, A E Yousef (eds). CRC. USA. pp:231-250.

Wade W N, L R Beuchat (2003a) Metabiosis of proteolytic moulds and Salmonella in raw, ripe tomatoes. J. Appl. Microbiol. 95:437450.

Wade W N, L R Beuchat (2003b) Proteolytic fungi isolated form decayed and damaged raw tomatoes and implications associated with changes in pericarp $\mathrm{pH}$ favorable for survival and growth of foodborne pathogens. J. Food Protect. 66:911-917. 
Wells J M, J E Butterfield (1997) Salmonella contamination associated with bacterial soft rot of fresh fruits and vegetables in the marketplace. Plant Dis. 81:867-872.

Wells J M, J E Butterfield (1999) Incidence of Salmonella on fresh fruits and vegetables affected by fungal rots of physical injury. Plant Dis. 83:722-726.

Wuytack E Y, L T P Duong, A Aertsen, K M F Reyns, D Marquenie, B De Ketelaere, B Masschalck, I Van Opstal, A M J Diels, C
W Michiels (2003) Comparison of sublethal injury induced in Salmonella enterica serovar Typhimurium by heat and by different nonthermal treatments. J. Food Protect. 66:31-37.

Zhuang R Y, L R Beuchat, F J Angulo (1995) Fate of Salmonella Montevideo on and in raw tomatoes as affected by temperature and treatment with chlorine. Appl. Environ. Microbiol. 61:21272131. 